\title{
Correction to: Cryoprotectant Toxicity: Facts, Issues, and Questions, by Best BP. Rejuvenation Res 2015;18(5):422-436; DOI: $10.1089 /$ rej.2014.1656
}

$\mathbf{I}^{\mathrm{N}}$

N THE OCTOBER 2015 issue of Rejuvenation Research (volume 18, number 5, pp. 422-436), the article entitled, "Cryoprotectant Toxicity: Facts, Issues, and Questions" by Benjamin P. Best requires correction. There was an error in the last sentence of the fifth paragraph on page 427. The word "toxicity" should have read "viability." The correct version of the sentence is as follows:

"Thus, $\mathrm{qv}^{*}$ is a measure of the vitrifying power of CPA solutions, and is inversely correlated with viability."

The online version of the article has been correction to reflect this change.

The author regrets this error. 